\title{
Aging changes of the testis in albino rat: light, electron microscopic, morphometric, immunohistochemical and biochemical study
}

\author{
S.M. Hussein ${ }^{1}$, A.B. El-Fadaly ${ }^{1}$, A.G. Metawea'1, B.E.A. Khaled ${ }^{1,2}$ \\ ${ }^{1}$ Anatomy and Embryology Department, Faculty of Medicine, Cairo University, Cairo, Egypt \\ 2Department of Anatomy, College of Medicine, Jouf University, Skaka, AlJouf, Saudi Arabia
}

[Received: 28 June 2019; Accepted: 27 August 2019]

Background: Aging has a deleterious effect on the morphology of the male reproductive system which might, in turn, lead to changes in spermatogenesis and consequently, decrease in both quality and quantity of spermatozoa.

Materials and methods: The present study elucidated the histological and ultrastructural changes of testes of adult albino rats during aging and applied morphometric measures to obtain quantitative data for these changes. The oxidative and antioxidative markers of aged testes were also assessed.

Results: The results documented the presence of age-related regressive structural changes of the testis accompanied with an increase in the apoptosis and a decrease in the proliferative capacity.

Conclusions: The biochemical results gave evidence of an imbalance between the oxidative damage and the antioxidant defence indicating increased oxidative stress of aged testis. (Folia Morphol 2020; 79, 3: 503-515)

Key words: aging, testis, morphological changes, oxidative markers, ultrastructure, proliferative cell nuclear antigen (PCNA), apoptosis

(caspase-3)

\section{INTRODUCTION}

Aging is a natural process comprising irreversible changes in all organs due to a number of endogenous and environmental factors. Changes of the testicular morphology are one of the effects of aging on male reproductive system. These changes might lead to a decrease in both the quality and quantity of spermatozoa [16].

It was believed that age influences the male reproductive capacity much less than it influences that of the females and that male fertility remains unaffected throughout their whole lifespan [33]. However, recent studies showed that advanced paternal age could be associated with a high incidence of congenital anomalies like Down syndrome, malignancies like leukaemias, central nervous system neoplasm and several neuropsychiatric disorders in the offspring $[16,48,49]$.

The seminiferous epithelium in rats might also be influenced by toxic substances which cause histopathologic and morphometric changes. The changes depend on the duration of exposure to these substances [14]. There is no definite time for the onset of the progressive testicular involution associated with advancing age. The most frequently observed histological change in the aging testes is variation in spermatogenesis in seminiferous tubules [43].

In both humans and rodents, aging-related atrophy was found to begin focally in the seminiferous tubules where atrophic tubules were often observed 
adjacent to tubules exhibiting normal spermatogenesis [40].

In the testicular tissue, with its high rates of metabolism and cell replication, oxidative stress can be especially damaging; a process which makes the antioxidant capacity of the tissue very important [45]. It appears that increased oxidative stress commonly occurs during the aging process and antioxidant status may significantly influence the effects of oxidative damage associated with advancing age and may even positively influence life span [25].

This study was designed to demonstrate the influence of aging on the structure of the testis of male albino rat and evaluate the apoptosis and the proliferative capacity of spermatogenic cells in different age groups. The study also aimed to assess associated biochemical changes that occur during aging and elicit the oxidative stress exerted on the aged testis.

\section{MATERIALS AND METHODS}

Thirty albino rats of Wistar strain were used in this study. The rats were obtained from the animal house of the Faculty of Medicine, Cairo University. The animals were acclimatised for a period of 2 weeks before carrying out the study. They were housed in separate clean cages, 5 rats/cage under standard laboratory and environmental conditions. They were given standard rodent food pellets and water ad libitum.

The rats were equally divided into three groups each of them consisted of ten rats as follows [41]:

- group I (early adult) ranging in age from 3 to 5 months (weight: 150-200 g);

- group II (middle-aged) ranging in age from 8 to 12 months (weight: 200-250 g);

- group III (senile) ranging in age from 20 to 24 months (weight $>300 \mathrm{~g}$ ).

All animals were anaesthetised and subsequently sacrificed. The testes of both sides were quickly extracted. Each testis was weighed (absolute weight) then relative weight was calculated (testis weight/ (body weight). The animals were handled and sacrificed in accordance to the ethical international guidelines for laboratory care and use. All the efforts to ensure minimal animal suffering were taken. The experiment protocol was approved by the committee of experimental animals (Cairo University Institutional Animal Care and Use Committee [CU-IACUC] approval number $\mathrm{CU} / \mathrm{II} / \mathrm{F} / 45 / 17)$.

The testes were processed and subjected to the following.

\section{Histopathological examination}

The testes were fixed in Bouin's solution and then were processed for paraffin sections of 4-6 $\mu \mathrm{m}$ thickness. Testes sections were cut and subjected to haematoxylin and eosin (H\&E), Masson's trichrome and periodic acid Schiff (PAS) staining.

\section{Electron microscopic examination}

Testicular specimens including the stroma and parenchyma were immersed in $2.5 \%$ glutaraldehyde (pH 7.4). Semithin sections were prepared at $0.5 \mu \mathrm{m}$ thickness and stained with $1 \%$ toluidine blue. UItrathin sections were double stained with $4 \%$ uranyl acetate and $0.1 \%$ lead citrate, examined and photographed by JEOL JEM 1010 transmission electron microscope (TEM) (Japan).

\section{Immunohistochemical studies}

The immunohistochemical study was performed as previously described for proliferating cell nuclear antigen (PCNA) and caspase-3 $[11,23]$. Testicular sections were deparaffinised, rehydrated followed by antigen retrieval, inactivation of endogenous peroxides and incubation with rabbit polyclonal anti-caspase-3 primary antibody (ab4051, 1/500, Abcam, USA) and rabbit polyclonal anti-PCNA antibody (ab18197, 1/500, Abcam, USA) for detection of apoptosis and proliferating spermatogenic cells, respectively. The secondary antibody used was biotinylated goat polyvalent antibody at $1 / 200$ dilution. Colour reaction was developed after adding diaminobenzidine. Paraffin-embedded mouse tonsillar tissue was used as a positive control. Negative controls were done through omission of the primary antibody in the automated staining protocol.

\section{Histomorphometric study}

A quantitative study was performed using Leica Qwin 500 image analyser computer system (Leica Imaging Systems, Cambridge, UK). The image analyser was first calibrated automatically to convert the measurement units (pixels) produced by image analyser programme into actual measurement units. Digital images were uniformly acquired and snapped at $\times 100$ magnification. All parameters were calculated in ten non-overlapping fields per slide in each age group.

The quantitative morphometric study included:

- thickness of epithelium of seminiferous tubule in $\mu \mathrm{m}$; 
- mean perimeter of seminiferous tubules in $\mu \mathrm{m}$;

- surface area of the seminiferous tubules in $\mu \mathrm{m}^{2}$;

- mean area per cent of collagen fibres deposition in Masson's trichrome stained sections;

- optical density of the basement membrane in PAS stained sections;

- number of PCNA-positive cells per seminiferous tubule;

- area per cent of caspase-3 immunoexpression in cytoplasm of spermatogenic cells.

Measurement of tissue level of malondialdehyde, nitric oxide and reduced glutathione

Testicular tissue homogenate was prepared as follows.

The tissue was homogenised in $5-10 \mathrm{~mL}$ cold buffer (i.e., $50 \mathrm{mM}$ potassium phosphate, pH 7.5. $1 \mathrm{mM}$ EDTA) per gram tissue then it was centrifuged at $100,000 \mathrm{~g}$ for $15 \mathrm{~min}$ at $4^{\circ} \mathrm{C}$. The supernatant was removed for assay and stored on ice. The testes tissue homogenates were prepared for assessment of malondialdehyde (MDA) as a biomarker for lipid peroxidation. The MDA assay was performed with thiobarbituric acid (TBA) test in the supernatant, according to the method suggested by Buege and Aust [2]. MDA reacts with TBA to give a red compound absorbing at $535 \mathrm{~nm}$. Measurement of glutathione (GSH) was based on the reduction of 5,5-dithiobis (2-nitrobenzoic acid) (DTNB) with reduced glutathione to produce a yellow compound [5]. The levels of nitric oxide (NO) in the testes homogenate were measured as previously described [15].

\section{Statistical analysis}

Quantification results were statistically described in terms of mean and standard deviation (mean \pm SD) and were analysed using statistical package SPSS version 24 by ANOVA with multiple comparisons Bonferroni post hoc testing. Differences with $p<0.05$ were considered statistically significant.

\section{RESULTS}

Light microscopic results Histological results

In early adult rats, the testis was covered by a well-defined capsule formed of tunica albuginea and tunica vasculosa. The testicular parenchyma was composed of several seminiferous tubules with narrow interstitial spaces containing loose areolar tissue in between. The seminiferous tubules were lined by stratified epithelium with two types of cells, the supporting Sertoli cells and the spermatogenic cells. The spermatogenic cells included spermatogonia, spermatocytes, round early spermatids and elongated late spermatids, arranged in that order from the basal compartment to the adluminal compartment of the seminiferous tubule (Fig. 1A, B).

The middle-aged rats' testes were comparable to group I in most of the cases. Slight structural changes were noted in only few cases where the seminiferous tubules showed both intercellular and intracellular vacuolisation in the seminiferous epithelium (Table 1; Fig. 1C, D).

Testes of senile rats revealed marked thickening of the tunica albuginea and tunica vasculosa with congested thick-walled arterioles. Vacuolisation of the germinal epithelium was frequently observed. Different forms of degenerative changes including pyknotic or fragmented karyorrhectic and necrotic nuclei were also observed. Atrophic hyalinised seminiferous tubules with arrest of spermatogenesis and tubules with numerous multinucleated giant cells were frequently observed in this age group.

The interstitial compartment of aged testes revealed obvious widening of the interstitial spaces plugged with lymphatic exudates, cytoplasmic vacuolisation of Leydig cells and Leydig cell hyperplasia. The blood vessels showed severe vascular wall thickening and lumen narrowing (Table 1; Fig. 1E-H).

\section{Ultrastructural results}

Examination of the seminiferous epithelium of group I by TEM showed Sertoli (supporting) cells resting on the basement membrane of the seminiferous tubule. Sertoli cells were bound to one another by Sertoli-to-Sertoli cell junctional complexes. Primary spermatocytes were present next to the spermatogonia. Early spermatids with pale round nuclei and peripherally located mitochondria near the cell membrane, spermatids with pro-acrosomal granules and mature sperms in the lumen of the seminiferous tubules were observed. The developed flagellum showing typical architecture of a cilium was seen in the tail of the sperms forming its axoneme with two single central microtubules and nine pairs of peripheral microtubules. The seminiferous epithelium was surrounded by a regular basal lamina and a lamina propria formed of few collagen fibres, myoid cells and endothelial lining of the peritubular capillaries (Fig. 2A-E). 

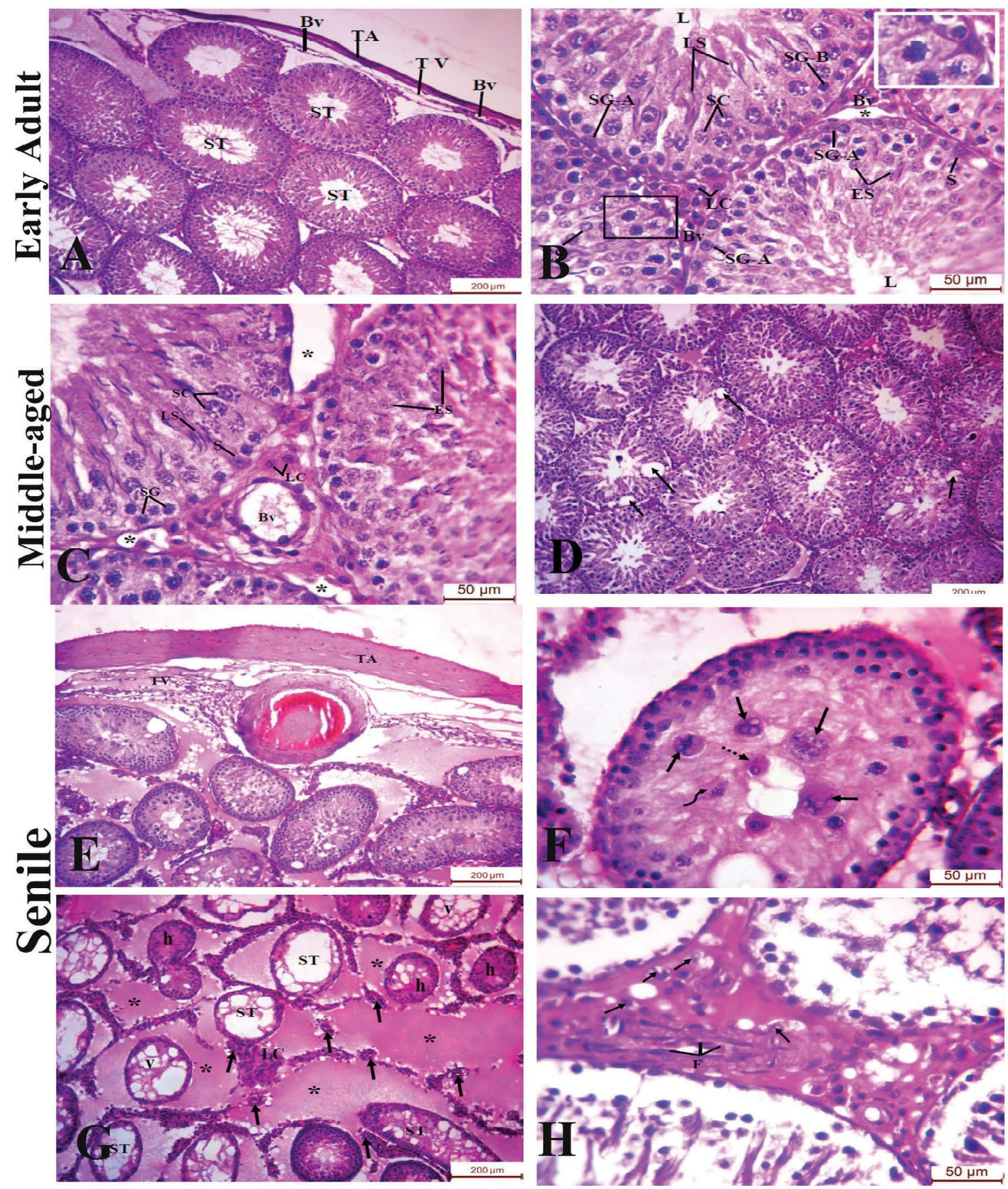

Figure 1. A, B. Haematoxylin and eosin stained sections of early adult group showing; A. The stroma of the testis formed of tunica albuginea (TA) and tunica vasculosa (TV) containing blood vessels (BV). The testicular parenchyma is seen formed of closely packed seminiferous tubules (ST) (H\&E $\times 100)$; B. Seminiferous tubule's epithelium is shown formed of supporting Sertoli cells (S) and spermatogenic cells as spermatogonia (SG), primary spermatocytes (SC), round early spermatids (ES) and elongated late spermatids (LS) arranged in many layers. Sertoli cell processes are shown surrounding the adjacent spermatogenic cells (inset). The interstitial tissue between ST show Clusters of Leydig cells (LC) around interstitial blood vessels (Bv) (H\&E $\times 400)$; C. Haematoxylin and eosin stained sections of middle aged group is shown comparable to early adult group where the seminiferous tubules are separated by narrow interstitial spaces $(H \& E \times 400)$; D. Some seminiferous tubules are shown with intracellular and intercellular vacuolisation (arrows) (H\&E $\times 100)$; E-H. The senile group, E. Haematoxylin and eosin stained sections show marked thickening of the tunica albuginea (TA) and tunica vasculosa (TV) appears also thickened with a large thickwalled congested arteriole (arrow) (H\&E $\times 100)$; $F$. The seminiferous tubules show numerous multinucleated giant cells (arrows), pyknotic germ cell (curved arrow) and necrotic cells are seen extruded in the lumen (dotted arrow) (H\&E $\times 400$ ); G. Extensively atrophic tubules (ST) with spermatogenic arrest, hyalinisation ( $h$ ) and vacuolisations (V) are observed. The blood vessels of the interstitium (arrows) show markedly thickened wall and extremely narrowed lumen. A massive widening of the peritubular spaces is evident $\left(^{*}\right)(H \& E \times 100) ; H$. Cytoplasmic vacuolisation of Leydig cells (arrows) are also demonstrated (H\&E $\times 400)$. 
Table 1. Histopathologic results detected by light microscope in middle age and senile group

\begin{tabular}{l}
\hline Group II \\
Seminiferous epithelium: \\
Intercellular and intracellular vacuolisation \\
Sporadic loss of spermatogenic cells \\
Hypospermatogenesis \\
Group III \\
Tunica albuginea: \\
Thickening \\
Tunica vasculosa: \\
Thickening \\
Congested thick walled arterioles \\
Seminiferous epithelium: \\
Vacuolisation \\
Spermatogenic arrest \\
Hyalinisation \\
Degenerative changes: pyknotic cells, necrotic cells \\
Multinucleated giant cells \\
Interstitial compartment: \\
Widening of interstitial spaces \\
Cytoplasmic vacuolisation of Leydig cell \\
Hyperplasia of Leydig cell \\
Vascular wall thickening and narrowing of the lumen \\
\hline
\end{tabular}

On the ultrastructural level, testes of middle-aged rats showed no apparent structural changes as compared to early adults. In only few cases vacuolisation of Sertoli cells cytoplasm was seen (Table 2; Fig. 2F).

In senile group, atrophic tubules showed an evident decrease in the spermatogonia, highly vacuolated Sertoli cells with marked increase in their lipid droplets and phagocytosed necrotic germ cells. The Sertoli-to-Sertoli cell junctional complexes showed atypical appearance. Necrotic spermatogonia with dark cytoplasm and pyknotic nuclei were also frequently observed. Wide spaces denoted sites of resided spermatogonia were seen. Primary spermatocytes frequently displayed blebbing and irregular dilatation of the perinuclear spaces. Abnormal spermatids with nuclear indentation and deformation of the proacrosomal granule were also detected. Abnormal sperms having double flagellum surrounded by a single membrane were also detected in this age group. Marked thickening of the wall of the seminiferous tubules (the basal lamina and lamina propria) were noticed in most tubules (Table 2; Fig. 3A-F).

\section{Gross anatomical results}

Right and left testes from all rats in the studied groups were weighed (absolute weight). Absolute and relative weights of the testes were registered and tabulated (Table 3).

\section{Histochemical results of the three age groups}

Periodic acid Schiff stained sections of group I and group II showed a moderate positive reaction in the basement membrane surrounding the seminiferous tubules. Most of germ cells showed negative reaction although elongated spermatids showed positive reaction. Group III revealed intense PAS reaction in the basement membrane surrounding the seminiferous tubules. These sections also showed thickened irregular basement membranes. There was a statistically significant increase in this measurement with advancing age (Fig. 4A-D).

Masson's trichrome stained sections in group I showed minimal collagen deposition in the tunica vasculosa, around the basement membranes of seminiferous tubules and blood vessels in the interstitium. This deposition was moderate in group II and extensive in group III. In certain areas there was invasion of tunica vasculosa by thick compact collagen bundles in senile group. There was a statistically significant increase in the mean area per cent of collagen fibres deposition measurements with advancing age (Fig. 4E-H).

\section{Immunohistochemical results of the three age groups}

Proliferating cell nuclear antigen. Immunohistochemical PCNA-stained testicular tissues in group I demonstrated positive immunoreactivity in most of spermatogonia and primary spermatocytes. The staining of the nuclei of the labelled cells was moderate to intense brown nuclear coloration. No reaction was seen in the nuclei of the early spermatids. Most of the stained sections of group II revealed intense positive immunoreactivity in basal spermatogonia and primary spermatocytes. In group III, PCNA stained sections revealed fewer immunoreactive basal spermatogenic cells. There was a statistically significant decrease in the mean number of positive stained cells between the studied groups with advancing age (Fig. 4I-L).

Caspase-3. Immunohistochemical staining of the testes in group I using caspase-3 showed weak caspase- 3 immunoexpression in the form of minimal diffuse brown cytoplasmic discoloration. Group II showed moderate caspase-3 immunoexpression, while group III showed strong positive caspase-3 

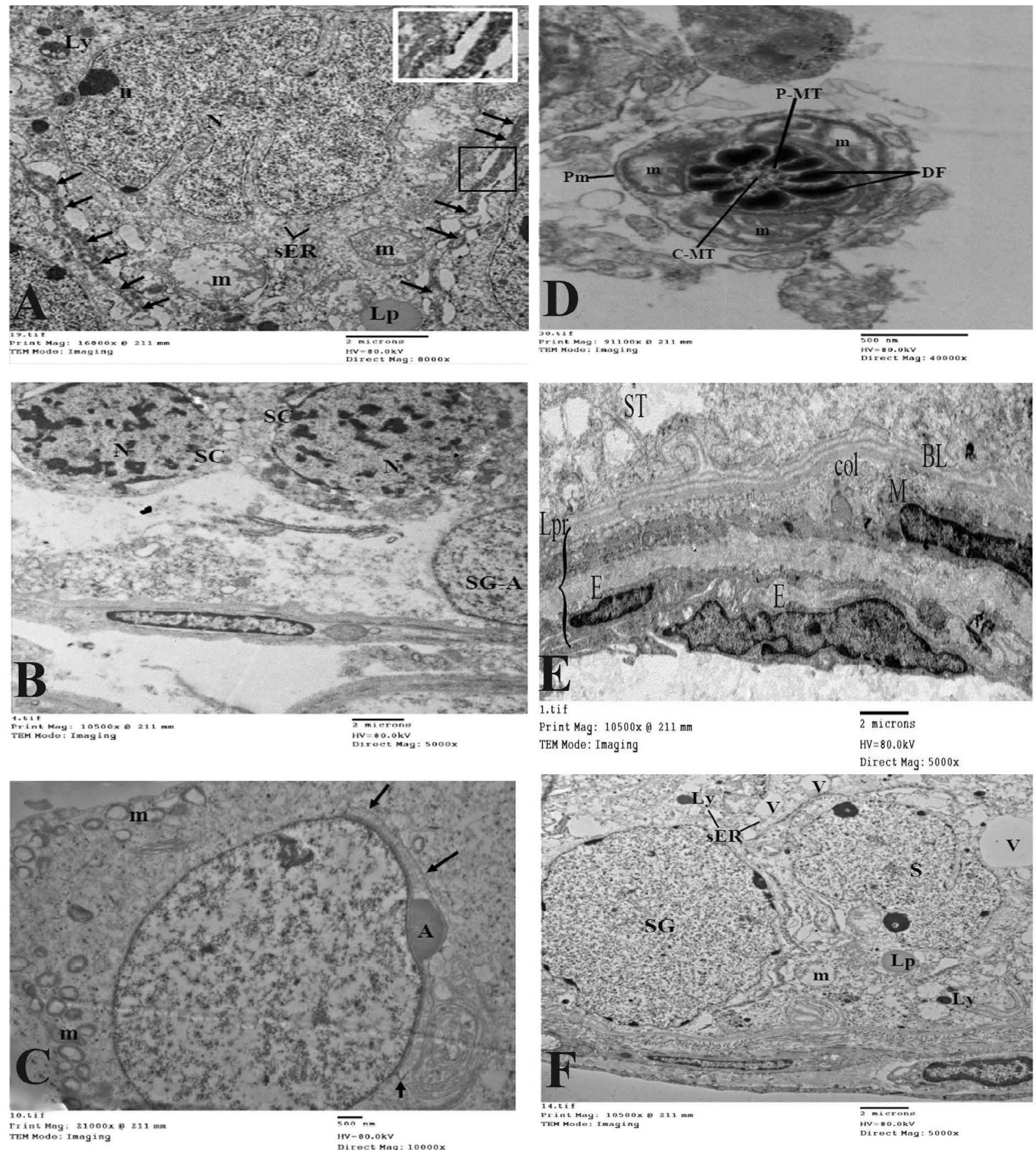

Figure 2. A-F. Electron photomicrographs in early adult rat testis showing; A. Sertoli cells with deeply indented euchromatic nuclei (N) with a prominent nucleolus ( $\mathrm{n}$ ). Sertoli cells are seen bound to one another by Sertoli-to-Sertoli cell junctional complexes (arrows) (inset); $m$ mitochondria, sER — smooth endoplasmic reticulum, Lp — lipid droplet, Ly — lysosomes (×8000); B. Primary spermatocytes (SC) showing widespread patches of heterochromatin in their nuclei are seen next to a spermatogonium $(\times 5000)$; C. Early spermatids are shown with pale round nucleus $(\mathrm{N})$, peripherally arranged small mitochondria $(\mathrm{m})$ with electron lucent centre, acrosomal granule $(\mathrm{A})$ and acrosomal cap (arrows) are also seen $(\times 10,000)$; D. A transverse sections in the middle piece of a mature sperm in the lumen of an early adult rat testis show an axoneme composed of two single central microtubules (C-MT) and 9 pairs of peripheral microtubules (P-MT) surrounded by 9 outer dense fibrils (DF) and circumferentially oriented sheath of mitochondria $(\mathrm{m})$ followed by plasma membrane $(\mathrm{Pm})(\times 40,000)$; $\mathbf{E}$. The wall of the seminiferous tubule is shown formed of a regular basal lamina $(\mathrm{BL})$ and a lamina propria (Lpr) formed of few collagen fibres (col), the myoid cells $(\mathrm{M})$ and endothelial cells $(\mathrm{E})$ bounding the lymphatic space $(\times 5000)$; F. A middle-aged rat testis shows variable sized vacuoles $(\mathrm{V})$ in the cytoplasm of Sertoli cells $(\times 5000)$. 
Table 2. Ultrastructural results detected by transmission electron microscope in middle age and senile group

\begin{tabular}{l}
\hline Group II \\
Sertoli cell: \\
Vacuolisation of Sertoli cell cytoplasm \\
Group III \\
Sertoli cell: \\
Increased lipid droplets \\
Increased vacuolisation \\
Impaired Sertoli-to-Sertoli cell junctional complex \\
Spermatogonia: \\
Necrotic nuclei and dark cytoplasm \\
Spermatocytes: \\
Blebbing and irregular dilatation of the perinuclear spaces \\
Spermatids: \\
Nuclear indentation and deformation of proacrosomal granule \\
Sperms: \\
Abnormal forms with double flagellum \\
Seminiferous tubule wall: \\
Thickening in both basal lamina and lamina propria
\end{tabular}

immunoexpression. It was also found that there was an increase in the mean area per cent of caspase-3 measurements between the three groups with advancing age. This difference was found to be statistically insignificant between groups I and II. However, the increase in the mean area per cent of caspase-3 stained sections was found to be statistically significant between groups I and III and between groups II and III (Fig. 4M-P).

\section{Histomorphometric results of the three age groups}

There was a statistically significant increase in the mean surface area and perimeter of the seminiferous tubule in the middle-aged group as compared to early adult. There was a decrease in these measures in the senile group. This decrease was found to be statistically significant when compared with middle-aged group, but statistically insignificant when compared with young adult group. There was also a statistically significant decrease in the mean thickness of epithelium measurements between the three studied groups with advancing age (Fig. 5A-C).

\section{Biochemical results of the three age groups}

The mean values of the oxidative markers; NO and MDA showed a statistically significant increase with advancing age, while that of the anti-oxidative marker; reduced GSH showed a statistically significant decrease with advancing age (Fig. 5D-F).

\section{DISCUSSION}

Aging has a deleterious effect on all organs. Recent studies have implied that aging impairs the male reproductive function and leads to production of malformed sperms in senile fathers which, in turn, give rise to offspring showing high prevalence of genetic abnormalities, childhood neoplasms and several neuropsychiatric disorders [16].

The morphological changes observed in the present study developed progressively, being insignificant in middle-aged rats, and started to be significant in the senile ones. Despite the slight alteration in testicular tissue, testes in this age group showed many layers of spermatogenic cells up to mature sperms in the lumen. On the other hand, some rats of the senile group show spermatogenic arrest with complete absence of sperms. In accordance to the current result, slight hypospermatogenesis in middle-aged group has been reported [20]. The current study observed many age-related regressive changes in the senile group. Of these changes, thickening of the tunica albuginea and tunica vasculosa was a constant finding in this age group. In agreement with the current data, fibrotic thickening of the tunica albuginea of the aged testes have been reported [13]. The age-related variations in the thickness of tunica albuginea were assumed to be due to different activeness of testes in different ages [35]. New layers of connective tissue were deposited around the testis with the advance of age, thereby leading to tunical wall thickening which could lead to several deleterious effects on spermatogenesis [12].

In the present study, the seminiferous tubules of the senile group showed pleopathological changes. The histopathologic changes in the current study endorse previous studies describing similar age-related changes [18, 20,34]. Some studies attributed seminiferous epithelium vacuolisation to Sertoli cell degeneration. Sertoli cell vacuolisation was considered a phenomenon usually appearing before extensive germ cell degeneration, and was believed to be an early indicator of Sertoli cell damage [31, 37]. The presence of seminiferous epithelial vacuoles was attributed to germ cell loss [36], while abnormal germ cells phagocytised by Sertoli cells lead to vacuolisation in the Sertoli cell cytoplasm [16]. It was concluded that the presence of vacuoles reflected diminished biological 

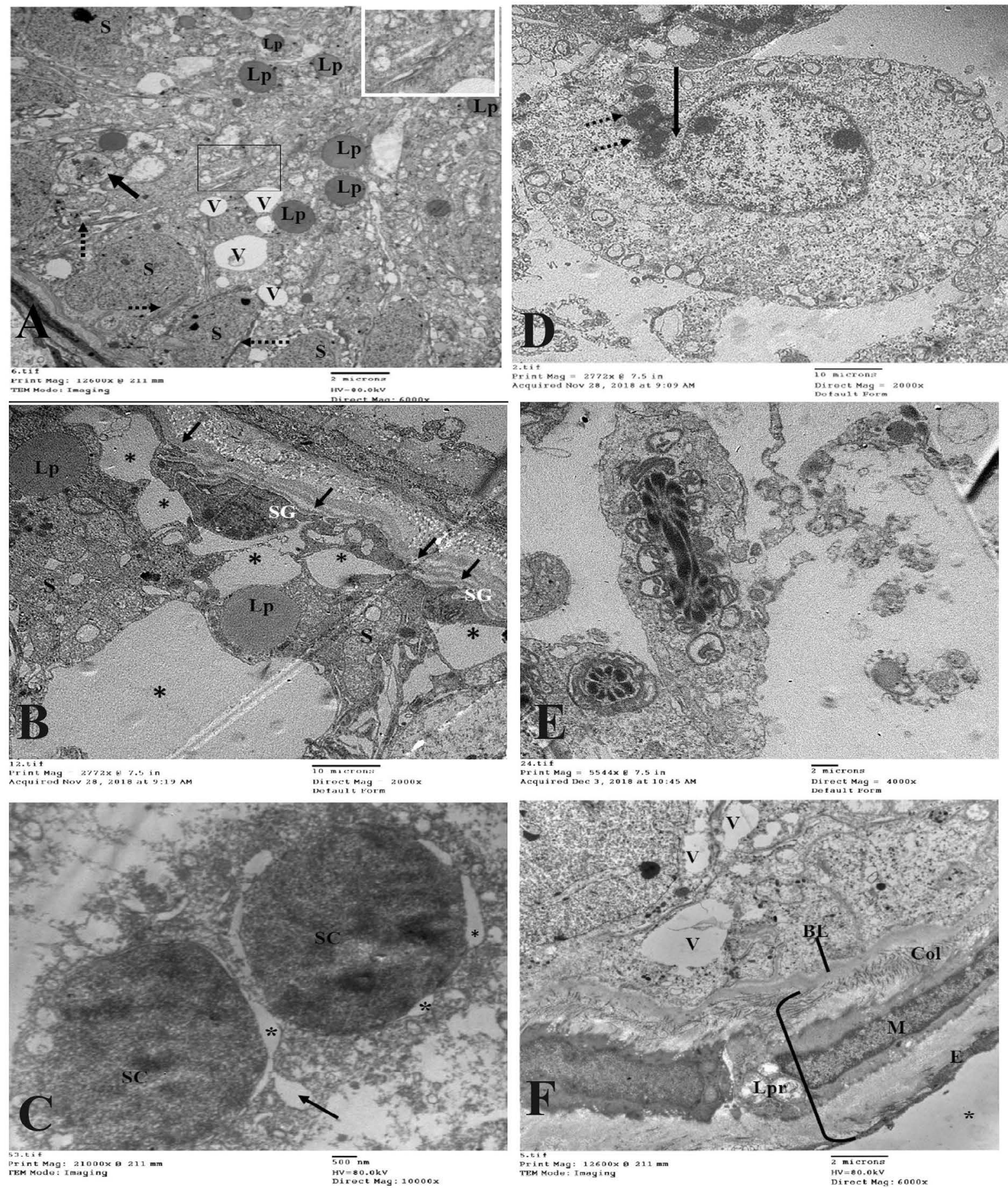

Figure 3. A-F. Electron photomicrographs of the senile group showing; A. Many lipid droplets (Lp), vacuoles (V) and phagocytized necrotic germ cell (thick arrow) in Sertoli cell cytoplasm. Few Sertoli-to-Sertoli junctional complexes can be identified (dotted arrows) with loss of their typical appearance (inset) $(\times 6000)$; B. The basal cells are also surrounded by empty intercellular spaces $\left({ }^{*}\right)$ denoting sites where germ cells have resided. Necrotic shrunken spermatogonia (SG) with pyknotic or fragmented nuclei and dark cytoplasm are seen $(\times 2000)$; C. Primary spermatocytes (SC) show blebbing (arrow) and dilatation of perinuclear spaces $\left({ }^{*}\right)(\times 10,000)$; D. Early spermatid is seen with indented nucleus (arrow), deformed acrosomal granule (dotted arrows) and absence of the acrosomal cap $(\times 2000)$; E. Sperms displaying double flagellum surrounded by a single membrane are seen $(\times 4000)$; $F$. Marked thickening of the basal lamina (BL) and lamina propria (Lpr) are seen in senile group; Col - collagen fibre, $\mathrm{m}$ - the myoid cells, $\mathrm{E}$ - endothelial cells, V - vacuoles $(\times 6000)$. 
Table 3. Absolute and relative weights of the testes in grams $(\mathrm{g})$ in the three age groups

\begin{tabular}{|c|c|c|c|c|c|}
\hline \multirow[t]{2}{*}{ Groups } & \multirow{2}{*}{$\begin{array}{l}\text { Body weight of rats }[\mathrm{g}] \\
\text { Mean } \pm \text { SD } \\
\text { (range in brackets) }\end{array}$} & \multicolumn{2}{|c|}{$\begin{array}{l}\text { Right testis } \\
\text { Mean } \pm \text { SD }\end{array}$} & \multicolumn{2}{|c|}{$\begin{array}{c}\text { Left testis } \\
\text { Mean } \pm \text { SD }\end{array}$} \\
\hline & & Absolute weight [g] & Relative weight [g] & Absolute weight [g] & Relative weight [g] \\
\hline Group I & $\begin{array}{c}171.9 \pm 14.2 \\
(155-195)\end{array}$ & $\begin{array}{l}0.98 \pm 0.4 \\
(0.25-1.4)\end{array}$ & $0.56 \pm 0.2$ & $\begin{array}{l}1.07 \pm 0.4 \\
(0.36-1.6)\end{array}$ & $0.61 \pm 0.2$ \\
\hline Group II & $\begin{array}{c}242.5 \pm 0.1 \\
(230-255)\end{array}$ & $\begin{array}{l}1.14 \pm 0.3 \\
(0.68-1.5)\end{array}$ & $0.43 \pm 0.1$ & $\begin{array}{l}1.17 \pm 0.4 \\
(0.65-1.6)\end{array}$ & $0.44 \pm 0.1$ \\
\hline Group III & $\begin{array}{c}315.0 \pm 31.6 \\
(300-375)\end{array}$ & $\begin{array}{c}1.39 \pm 0.2 \\
(1.2-1.7)\end{array}$ & $0.44 \pm 0.1$ & $\begin{array}{c}1.51 \pm 0.1 \\
(1.4-1.6)\end{array}$ & $0.48 \pm 0.1$ \\
\hline
\end{tabular}

function of Sertoli cells with aging [19, 39]. The opinion suggested by the current study is that vacuolisation of seminiferous epithelium is multifactorial as the ultrastructural results showed widened spaces next to the basement membranes suggestive of spermatogonial germ cell loss in addition to marked vacuolisation of the adjacent Sertoli cells. Also, the presence of phagocytosed necrotic germ cells in the Sertoli cell cytoplasm gave an indication that this process could be one of the causes of Sertoli cell vacuolisation.

The ultrastructural changes that we have noted in the Sertoli cell cytoplasm were consistent with previous studies $[19,30,28]$. It was suggested that lipid accumulation is due to degeneration of the germ cells that have been phagocytised by Sertoli cells [42].

The disruption in Sertoli-to-Sertoli junctions has been incriminated in abnormal spermatogenesis and subsequent degeneration of immunological barrier given by the blood testis barrier in the aged groups $[19,39]$. In agreement with the histopathologic changes observed in the present study, regressed tubules with degenerated germ cells and large intercellular spaces in senile Brown Norway rats were reported [24].

In the present study, affection of the process of spermiogenesis in senile rats and presence of abnormal spermatids was evident. In agreement with these results, abnormalities principally affecting the acrosome and flagellum were also previously reported in aged hamsters $[28,44]$. Abnormalities affecting the developing sperm flagellum, including sperms with double flagellum, were related to mitochondrial changes originating during spermiogenesis process [44]. Spermatids that displayed mitochondria arranged in a disordered fashion were previously reported [19]; an alteration that was clearly documented in the present study.

The presence of multinucleated giant cells in the current study was consistent with previous studies who reported the occurrence of multinucleated giant cells as a characteristic feature of aging testis $[4,17$, $18,22,39]$. The presence of multinucleated giant cells could be attributed to impaired spermatogenesis or inability of tetraploid primary spermatocytes to complete meiotic division $[29,38]$.

Fourteen caspases have been implicated in the apoptotic pathway cascade. Among these, caspase-3 is considered to be a major execution protease and has critical role in apoptosis of germ cells [21]. The accelerated apoptotic events of germ cells have recently attracted great attention [10, 16, 19]. In agreement to our study, there is an increased apoptosis in the testicular germ cells with advancing age, supporting the idea that changes would occur in sperm DNA quality with aging [46].

The present study indicated that regressive alterations of the seminiferous tubules in the senile rats varied from sporadic loss of spermatogenic cells and hypospermatogenesis up to maturation arrest and hyalinisation. The morphometric results confirmed the structural findings regarding atrophy and regression of the seminiferous tubules. The reduction in the morphometric parameters might be caused by regression of the germ cell population and increasing apoptosis in the spermatogonia with age.

Arrest or hypospermatogensis and reduced thickness encountered many factors including increase in the apoptotic activity as expressed by caspase-3 concomitant with a decrease in the proliferative capacity as expressed by PCNA. Assessment of the proliferative capacity of testicular cells in the current study was done using immunohistochemical staining with PCNA. In contrary to other methods, PCNA immunostaining seemed to be a reasonable method for evaluating proliferation, as it is a sensitive marker of the proliferative events in the process of spermatogenesis. It is also simple, cheap, accurate and promising for application in clinical field [9]. Diminished prolifera- 
Early adult
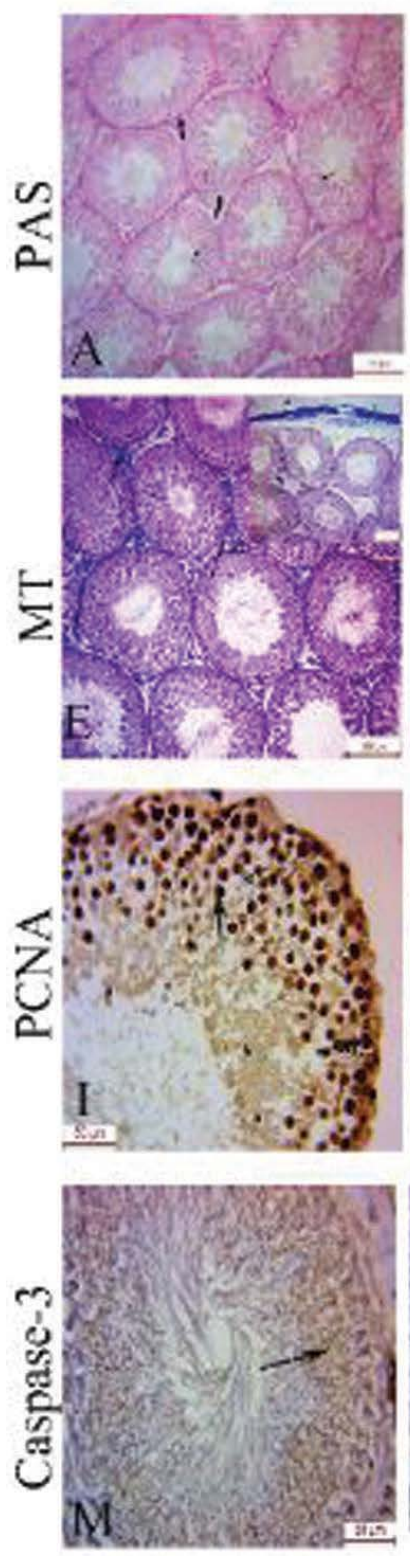

Middle-aged
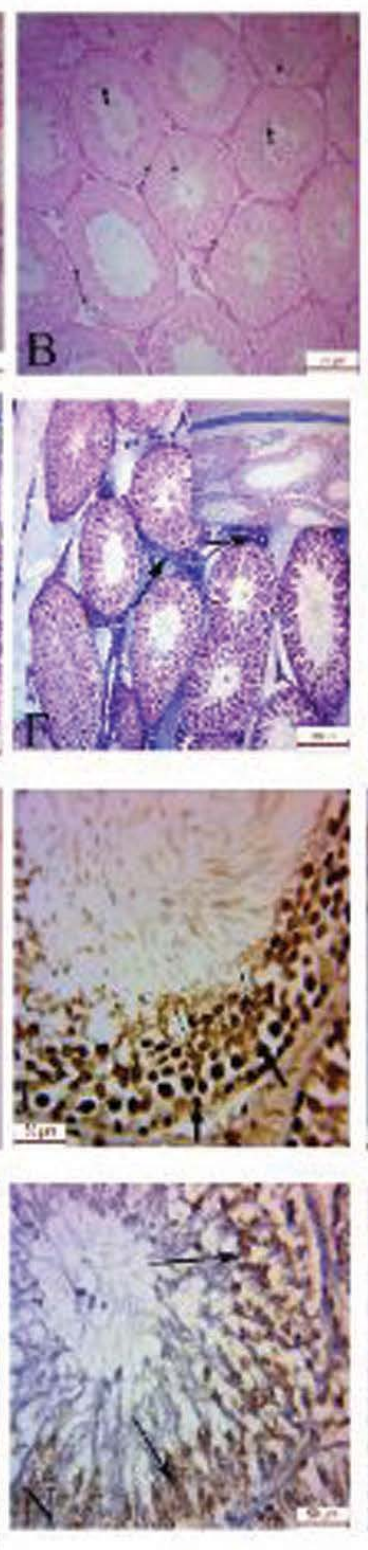

Senile
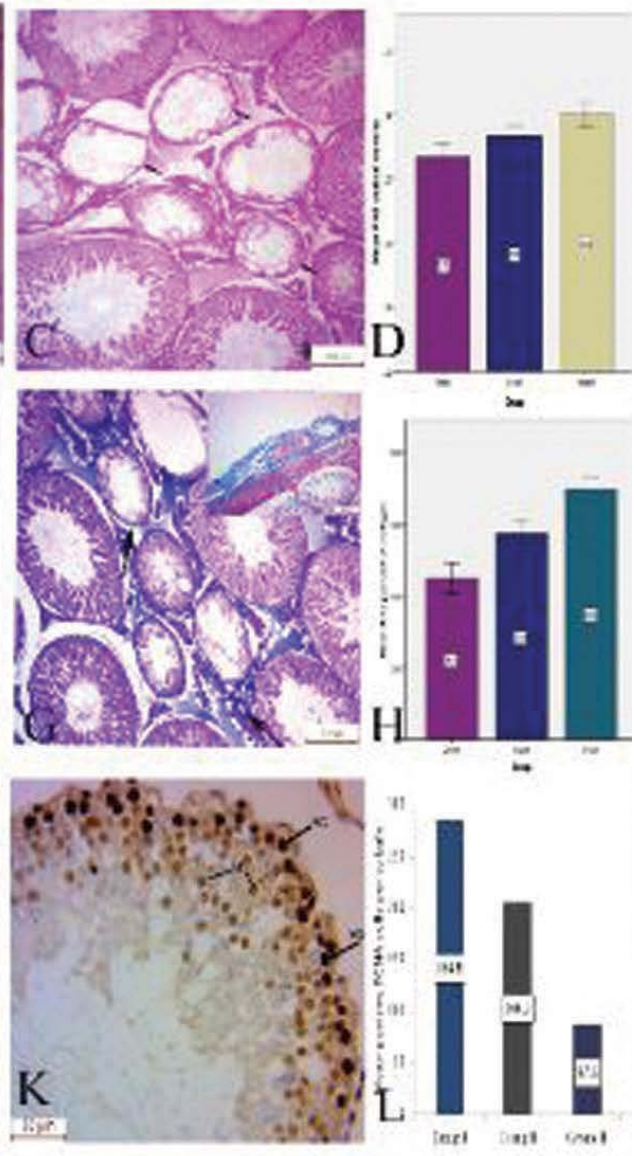

sen

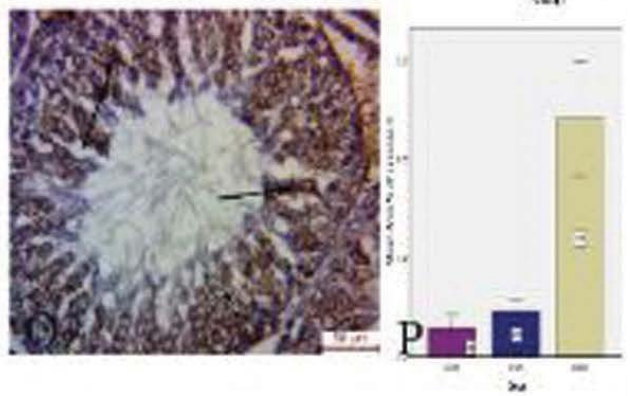

Figure 4. Periodic acid Schiff (PAS) stained sections $(\times 100)$; A. In early adult group; B. In middle aged group show a moderate PAS reaction in the basement membrane and in elongated spermatids (arrows); C. Senile group testes show intense PAS reaction (arrows) in the basement membrane surrounding the seminiferous tubules; D. Statistically significant increase in the optical density of PAS staining with advancing age is shown. Masson trichrome $(\mathrm{MT})$ stained sections $(\times 100)$ show; E. Group I with minimal collagen deposition around basement membranes and blood vessels in the interstitium (arrows); F. The middle-aged group show moderate deposition of collagen fibres (arrows). No obvious changes in tunical albuginea (TA) and vasculosa (TV) of middle aged as compared to group I (inset); G. Senile group shows dense collagen fibres deposition (arrow). Extensive collagen bundles deposition in tunica albuginea and tunica vasculosa is shown (inset); $\boldsymbol{H}$. The mean area per cent of collagen fibres deposition is increased with advancing age. Proliferative cell nuclear antigen (PCNA) immunoreactivity $(\times 400)$; I. Early adult group shows a strong positive PCNA immunoreactivity in the nuclei of spermatogonia (SG) and primary spermatocytes (SC); J. In middle-aged group, moderate PCNA immunoreactivity (thin arrows) in some spermatogenic cells appear among strong positive PCNA immunoreactivity (thick arrows); $\mathbf{K}$. Senile group shows markedly reduced germ cells with intense positive immunoreactivity; L. The mean number of positive stained cells shows a statistically significant decrease with advancing age. Caspase- 3 immuoexpression $(\times 400)$;

M. Early adult group shows weak caspase-3 immunoreactivity of spermatogenic cells with minimal brown cytoplasmic discolouration; $\mathbf{N}$. In middle-aged, moderate caspase-3 immunoexpression (arrow) in some spermatogenic cells is shown; $\mathbf{0}$. Senile group shows strong positive caspase-3 immunoreactivity in most of the spermatogenic cells (arrows); $\mathbf{P}$. The mean area per cent of caspase-3 measurements show an increase with advancing age which is statistically significant between group I and III. 


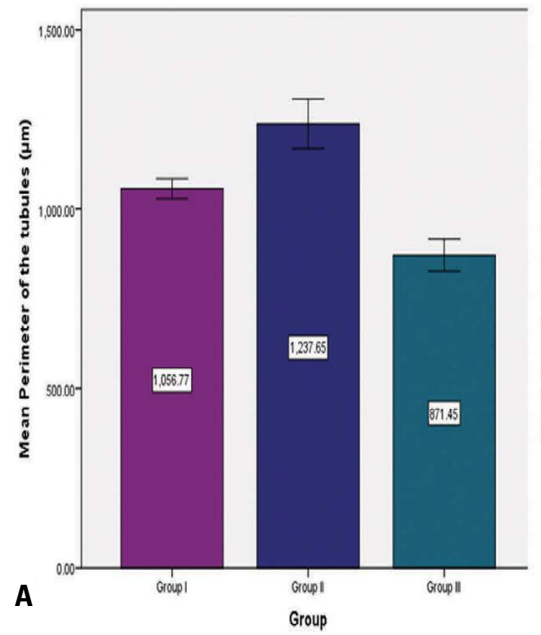

Perimeter

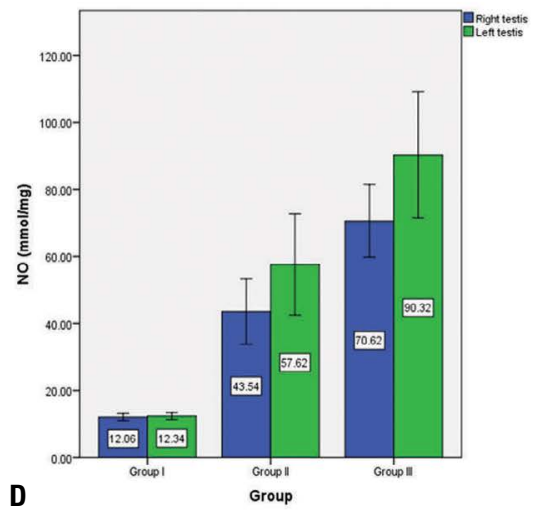

Nitric oxide

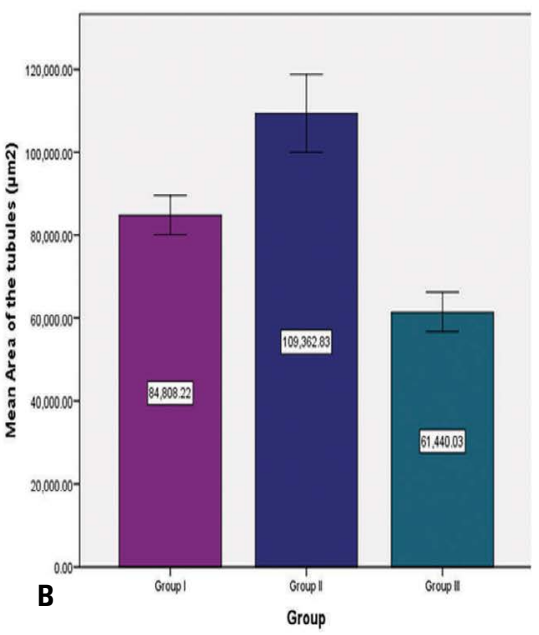

Surface area

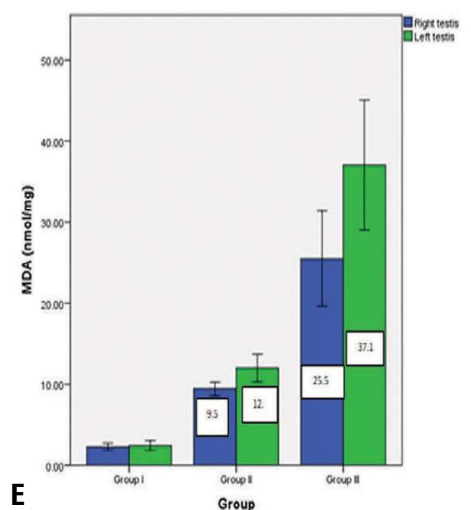

Malondialdehyde

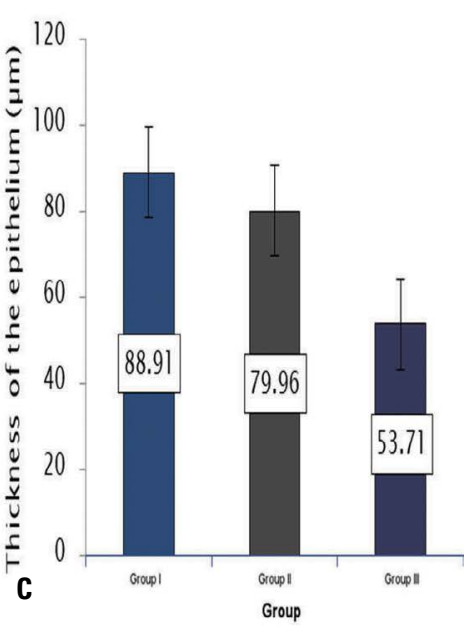

Epithelial thickness

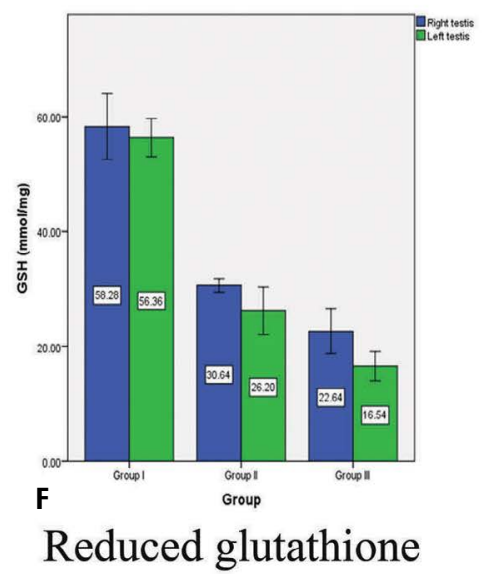

Figure 5. Morphometric measures of the three age groups; A. The mean surface area; B. The perimeters of the seminiferous tubules show a significant increase in middle age group as compared to early adult. The senile group showed a decrease in the mean surface area and perimeter of the seminiferous tubules. This decrease was found to be statistically significant when compared with the middle-aged group; C. The mean epithelial thickness shows a statistically significant decrease between with advancing age. Biochemical results of the three age groups; D. Nitric oxide (NO); E. Malondialdehyde (MDA); F. Reduced glutathione (GSH) show a statistically significant increase in the mean values of NO and MDA with advancing age and a statistically significant decrease in the mean values of GSH with advancing age.

tion of the germ cells is considered a characteristic finding during testicular aging [19, 32].

Apoptosis is essential for spermatogenesis under normal conditions but the balance between proliferation of spermatogonia and apoptosis of different germ cell types might be disturbed with aging [16, 32].

Apart from senile changes in seminiferous epithelium, alterations in the basement membrane of the seminiferous tubules on both histological and ultrastructural levels as well as histochemically using PAS stain was concomitant with increased basement membrane thickness has been previously linked to spermatogenic arrest and fibrosis [6].
It seems that the vascular changes observed in the senile animals in the present study played an important role in most of the histopathological changes observed in this age group as these vascular changes were common in the interstitium surrounding the atrophic seminiferous tubules. This correlation comes in line with other authors who mentioned that the development of tubular involution with advancing age is similar to that observed after experimental ischaemia, suggesting that vascular lesions may be involved in age-related testicular atrophy [43].

In accordance to the current results regarding the Leydig cells, previous authors linked the decrease in 
endocrine activity in aged Leydig cells to involution in organelle content in advanced age [3]. One interesting phenomenon noted in the present study was the increase in the number of Leydig cells in the interstitium surrounding atrophic tubules. Similarly, other researchers recorded an increase in the Leydig cells size and number with aging $[6,47]$. The increase in the number and size of Leydig cells might indicate a compensatory process of aged testicular tissue.

Examination of the biochemical changes including oxidative and antioxidative markers is of crucial importance in studying aging of the tissues as oxidative stress has a great role in the regressive changes associated with advanced age, thus the present study has measured NO, MDA and reduced GSH in testicular tissue being the most important markers maintaining the redox state of the cells. The senescence processes in reproductive cells induces free radicals accumulation in sperm mitochondria and Leydig cells, resulting in the disruption of sperm telomere, steroidogenesis in the Leydig cells and the presence of mitochondrial DNA in both cells [7].

In the current study, the imbalance between oxidative and antioxidative markers made the senile testis exposed to oxidative stress contributing to the regressive changes in this group.

Several studies attributed the age-related germ cell apoptosis to the oxidative/antioxidative imbalance $[1,8,27]$. With aging, the enzymatic defence mechanisms protecting the germinal epithelium cannot cope with the extensive oxidative damage and therefore apoptotic events increases especially in germ cells. Thus, aged testes undergo profound histological and morphological alterations leading to a reduction in testicular function [26].

\section{CONCLUSIONS}

It appears that aging of the testis and its potential contribution to male infertility and to adverse health outcome is still a matter of thorough investigation in recent researches. Many theories have been developed to establish the cause and mechanism of aging of male reproductive system. However, no single theory could explain the exact cause of male reproductive senescence. The results of the current study documented the presence of age-related regressive changes of the testes augmented by immunohistochemical and biochemical data. The biochemical results gave evidence of an imbalance between oxidative damage and anti-oxidant defence in aged testis.

\section{REFERENCES}

1. Beattie MC, Chen $\mathrm{H}$, Fan J, et al. Aging and luteinizing hormone effects on reactive oxygen species production and DNA damage in rat Leydig cells. Biol Reprod. 2013; 88(4): 100, doi: 10.1095/biolreprod.112.107052, indexed in Pubmed: 23486914.

2. Buege J, Aust S. Microsomal lipid peroxidation. Methods Enzymol. 1978: 302-310, doi: 10.1016/s00766879(78)52032-6.

3. Chen H, Zirkin BR. Long-term suppression of Leydig cell steroidogenesis prevents Leydig cell aging. Proc Natl Acad Sci U S A. 1999; 96(26): 14877-14881, doi: 10.1073/ pnas.96.26.14877, indexed in Pubmed: 10611306.

4. Creasy D, Bube A, de Rijk E, et al. Proliferative and nonproliferative lesions of the rat and mouse male reproductive system. Toxicol Pathol. 2012; 40(6 Suppl): 40S-40121S, doi: 10.1177/0192623312454337, indexed in Pubmed: 22949412.

5. Crowley C, Gillham B, Thorn M. A direct enzymic method for the determination of reduced glutathione in blood and other tissues. Biochem Med. 1975; 13(3): 287-292. doi: 10.1016/0006-2944(75)90087-3.

6. Dakouane M, Bicchieray L, Bergere $M$, et al. A histomorphometric and cytogenetic study of testis from men 29-102 years old. Fertil Steril. 2005; 83(4): 923-928, doi: 10.1016/j.fertnstert.2004.12.005, indexed in Pubmed: 15820802

7. Desai N, Sabanegh E, Kim T, et al. Free radical theory of aging: implications in male infertility. Urology. 2010; 75(1): 14-19, doi: 10.1016/j.urology.2009.05.025, indexed in Pubmed: 19616285.

8. Drew $B$, Leeuwenburgh $C$. Aging and the role of reactive nitrogen species. Ann N Y Acad Sci. 2002; 959: 66-81, doi: 10.1111/j.1749-6632.2002.tb02084.x, indexed in Pubmed: 11976187.

9. Foley JF, Dietrich DR, Swenberg JA, et al. Detection and evaluation of proliferating cell nuclear antigen (PCNA) in rat tissue by an improved immunohistochemical procedure. J Histotechnol. 1991; 14(4): 237-241, doi: 10.1179 /014788891794666745.

10. Frungieri MB, Calandra RS, Bartke $A$, et al. Ageing and inflammation in the male reproductive tract. Andrologia. 2018; 50(11): e13034, doi: 10.1111/and.13034, indexed in Pubmed: 29740839.

11. Fu L, Chen $\mathrm{YH}, \mathrm{Xu} \mathrm{S}$, et al. Vitamin D deficiency impairs testicular development and spermatogenesis in mice. Reprod Toxicol. 2017; 73: 241-249, doi: 10.1016/j.reprotox.2017.06.047, indexed in Pubmed: 28655646.

12. Goedken MJ, Kerlin RL, Morton D. Spontaneous and age-related testicular findings in beagle dogs. Toxicol Pathol. 2008; 36(3): 465-471, doi: 10.1177/0192623308315670, indexed in Pubmed: 18467685.

13. Gofur MR, Khan M, Karim MR, et al. Histomorphology and histochemistry of testis of indigenous bull (Bos indicus) of Bangladesh. Bangladesh J Vet Med. 1970; 6(1): 67-74, doi: 10.3329/bjvm.v6i1.1341.

14. Golalipour MJ, Azarhoush R, Ghafari S, et al. Formaldehyde exposure induces histopathological and morphometric changes in the rat testis. Folia Morphol. 2007; 66(3): 167-171.

15. Green L, Wagner D, Glogowski J, et al. Analysis of nitrate, nitrite, and [15N]nitrate in biological fluids. Anal Biochem. 1982; 126(1): 131-138, doi: 10.1016/00032697(82)90118-x.

16. Gunes S, Hekim GN, Arslan MA, et al. Effects of aging on the male reproductive system. J Assist Reprod Genet. 2016; 33(4): 441-454, doi: 10.1007/s10815-016-0663-y, indexed in Pubmed: 26867640. 
17. Hikim AP, Vera $Y$, Vernet $D$, et al. Involvement of nitric oxide-mediated intrinsic pathway signaling in age-related increase in germ cell apoptosis in male Brown-Norway rats. J Gerontol A Biol Sci Med Sci. 2005; 60(6): 702-708, doi: 10.1093/gerona/60.6.702, indexed in Pubmed: 15983171.

18. Horn R, Pastor LM, Moreno E. Morphological and morphometric study of early changes in the ageing golden hamster testis. J Anat. 1996; 188(1): 109-117.

19. Jiang H, Zhu WJ, Li J, et al. Quantitative histological analysis and ultrastructure of the aging human testis. Int Urol Nephrol. 2014; 46(5): 879-885, doi: 10.1007/s11255-0130610-0, indexed in Pubmed: 24277275.

20. Johnson L, Petty CS, Neaves WB. Influence of age on sperm production and testicular weights in men. J Reprod Fertil. 1984; 70(1): 211-218, doi: 10.1530/jrf.0.0700211, indexed in Pubmed: 6694139.

21. Kim JM, Ghosh SR, Weil AC, et al. Caspase-3 and caspase-activated deoxyribonuclease are associated with testicular germ cell apoptosis resulting from reduced intratesticular testosterone. Endocrinology. 2001; 142(9): 3809-3816, doi: 10.1210/endo.142.9.8375, indexed in Pubmed: 11517157.

22. Kühnert B, Nieschlag E. Reproductive functions of the ageing male. Hum Reprod Update. 2004; 10(4): 327-339, doi: 10.1093/humupd/dmh030, indexed in Pubmed: 15192059.

23. Lee JD, Lee TH, Cheng WH, et al. Involved intrinsic apoptotic pathway of testicular tissues in varicocele-induced rats. World J Urol. 2009; 27(4): 527-532, doi: 10.1007/ s00345-008-0367-8, indexed in Pubmed: 19145435.

24. Levy S, Serre V, Hermo L. The effects of aging on the seminiferous epithelium and the blood - testis barrier of the Brown Norway rat. J Androl. 1999; 20(3): 356-365.

25. Lobo V, Patil A, Phatak A, et al. Free radicals, antioxidants and functional foods: Impact on human health. Pharmacogn Rev. 2010; 4(8): 118-126, doi: 10.4103/09737847.70902, indexed in Pubmed: 22228951.

26. Matzkin ME, Miquet JG, Fang $Y$, et al. Alterations in oxidative, inflammatory and apoptotic events in short-lived and long-lived mice testes. Aging (Albany NY). 2016; 8(1): 95-110, doi: 10.18632/aging.100875, indexed in Pubmed: 26805572.

27. Merendino RA, Salvo F, Saija A, et al. Malondialdehyde in benign prostate hypertrophy: a useful marker? Mediators Inflamm. 2003; 12(2): 127-128, doi: 10.1080/096293503 1000097745, indexed in Pubmed: 12775364

28. Morales E, Horn R, Pastor LM, et al. Involution of seminiferous tubules in aged hamsters: an ultrastructural, immunohistochemical and quantitative morphological study. Histol Histopathol. 2004; 19(2): 445-456.

29. Neuman SL, Lin TL, Heste PY. The effect of dietary carnitine on semen traits of white Leghorn roosters. Poult Sci. 2002; 81 (4): 495-503, doi: 10.1093/ps/81.4.495, indexed in Pubmed: 11989749.

30. Paniagua R, Martinez-Onsurbe $P$, Santamaria L, et al. Quantitative and ultrastructural alterations in the lamina propria and Sertoli cells in human cryptorchid testes. Int J Androl. 1990; 13(6): 470-487, doi: 10.1111/j.1365-2605.1990. tb01054.x, indexed in Pubmed: 1982882.

31. Paniagua R, Nistal M, Sáez FJ, et al. Ultrastructure of the aging human testis. J Electron Microsc Tech. 1991; 19(2): 241-260, doi: 10.1002/jemt.1060190209, indexed in Pubmed: 1748904.

32. Pastor LM, Zuasti A, Ferrer $C$, et al. Proliferation and apoptosis in aged and photoregressed mammalian seminiferous epithelium, with particular attention to rodents and humans. Reprod Domest Anim. 2011; 46(1): 155-164, doi: 10.1111/j.1439-0531.2009.01573.x, indexed in Pubmed: 20149139.

33. Paulson RJ, Milligan RC, Sokol RZ. The lack of influence of age on male fertility. Am J Obstet Gynecol. 2001; 184(5): 818-22; discussion 822, doi: 10.1067/mob.2001.113852, indexed in Pubmed: 11303188.

34. Perheentupa A, Huhtaniemi I. Aging of the human ovary and testis. Mol Cell Endocrinol. 2009; 299(1): 2-13, doi: 10.1016/j. mce.2008.11.004, indexed in Pubmed: 19059459.

35. Pop OT, Cotoi CG, Plesea IE. Histological and ultrastructural analysis of the seminiferous tubule wall in ageing testis. Rom J Morphol Embryol. 2011; 52(1): 241-248.

36. Pop OT, Cotoi CO, Plesea IE. Correlations between intralobular interstitial morphological changes and epithelial changes in ageing testis. Rom J Morphol Emryol. 2011; 52(1): 339-347.

37. Russell L, Ettlin R, Hikim A, et al. Histological and histopathological evaluation of the testis. Int J Androl. 1993; 16(1): 83-83, doi: 10.1111/j.1365-2605.1993.tb01156.x.

38. Russell LD, Hikim AP, Overbeek PA, et al. Testis structure in the sys (symplastic spermatids) mouse. Am J Anat. 1991; 192(2): 169-182, doi: 10.1002/aja.1001920206, indexed in Pubmed: 1759682.

39. Santiago J, Silva JV, Alves MG, et al. Testicular aging: an overview of ultrastructural, cellular, and molecular alterations. J Gerontol A Biol Sci Med Sci. 2019; 74(6): 860-871, doi: 10.1093/gerona/gly082, indexed in Pubmed: 29688289.

40. Schoenfeld HA, Hall SJ, Boekelheide K. Continuously proliferative stem germ cells partially repopulate the aged, atrophic rat testis after gonadotropin-releasing hormone agonist therapy. Biol Reprod. 2001; 64(4): 1273-1282, doi: 10.1095/biolreprod64.4.1273, indexed in Pubmed: 11259276.

41. Sengupta P. A scientific review of age determination for a laboratory rat: how old is it in comparison with human age? Biomed Int. 2015; 2(2): 81-89.

42. Sinha Hikim AP, Wang $C$, Lue $Y$, et al. Spontaneous germ cell apoptosis in humans: evidence for ethnic differences in the susceptibility of germ cells to programmed cell death. J Clin Endocrinol Metab. 1998; 83(1): 152-156, doi: 10.1210/ jcem.83.1.4485, indexed in Pubmed: 9435433.

43. Standring S, Ariana L, Alan J. Abdomen and Pelvis: Male reproductive system. In: Gray's anatomy, the anatomical basis of clinical practice, 41 th ed. Churchill Livingstone Elsevier, London 2015: 1272-1286.

44. Syntin P, Robaire B. Sperm structural and motility changes during aging in the Brown Norway rat. J Androl. 2001; 22(2): 235-244.

45. Turner TT, Lysiak JJ. Oxidative stress: a common factor in testicular dysfunction. J Androl. 2008; 29(5): 488-498, doi: 10.2164/jandrol.108.005132, indexed in Pubmed: 18567643.

46. Wyrobek AJ, Eskenazi B, Young S, et al. Advancing age has differential effects on DNA damage, chromatin integrity, gene mutations, and aneuploidies in sperm. Proc Natl Acad Sci U S A. 2006; 103(25): 9601-9606, doi: 10.1073/ pnas.0506468103, indexed in Pubmed: 16766665.

47. Xu YC, Jing LI, Liang WB. evaluation on changes of testicular histology in aging men. J Reprod Contracept. 2013; 24(4): 199-204.

48. Yip BH, Pawitan Y, Czene K. Parental age and risk of childhood cancers: a population-based cohort study from Sweden. Int J Epidemiol. 2006; 35(6): 1495-1503, doi: 10.1093/ije/dyl177, indexed in Pubmed: 17008361.

49. Zhu JL, Madsen KM, Vestergaard M, et al. Paternal age and congenital malformations. Hum Reprod. 2005; 20(11): 3173-3177, doi: 10.1093/humrep/dei186, indexed in Pubmed: 16006461. 